\title{
Internet of Things Enabled Smart Microgrid
}

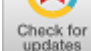

\author{
Sonali Dash, Ritu Santra
}

\begin{abstract}
In the era of emerging technologies internet of things (IoT) and smart power grid, this two are major technology which would boost up the development of any country because of its perspective of smart and renewable technique. A microgrid is a small-scale localized energy grid with the capability to control the various electrical parameters and can be operated autonomously. This microgrid technology can be implemented in both rural and urban areas. In this paper, the author proposes the design of a smart microgrid system enabled IOT for a smart country. A microgrid is an excellent solution for providing a continuous supply of power during the failure of the main grid (blackouts issues). It can also be used in industries for providing additional power, and most importantly it can be implemented in areas like an island or remote/rural areas. The IoT can be a smart approach that offers the solution for detecting the fault and a convenient real-time technique to control and monitor the consumption of energy. In the present time, the non-renewable electrical network system is outdated due to the increasing demand for electrical energy. We have also proposed a smart energy distribution of power to the load by turning the appliances in power saving mode by the help of IoT platform. This smart microgrid can be installed in every house of the country for promoting smart energy distribution, a smart way of energy saving, and ecofriendly technique, this can connect parallel to the main grid supply. IoT will also help to monitor and detect the fault in a very faster manner. It will detect the fault in the microgrid with help of current sensor and voltage sensor installed in the transmission line. The current and voltage data collected from the sensors will be continuously sent to the microcontroller with the help of a Wi-Fi module and IoT platform. The microcontroller Raspberry pi 3 will store the data and it will continuously monitor the loads connected to the microgrid by the Cayenne's IoT platform. The loads can be also triggered by the help of IoT platforms. The microgrid is incorporated with the net metering concept to make the power system reliable.
\end{abstract}

Keywords: Microgrid, Internet of things, Smart country, fault detection, Raspberry pi 3, Cayenne's IOT, Smart energy distribution, Smart load management, Net metering.

\section{INTRODUCTION}

In India, the non-renewable Electric grid is insufficient to meet the demand of increasing population. The Smart microgrid can be installed in each and every house of the

Revised Manuscript Received on August 30,2020.

* Correspondence Author

Sonali Dash*, Student, Department of Electrical and Electronics Engineering, SRM Institute of Science and Technology, Chennai, Tamil Nadu, India. E-mail: sonalidash1316@gmail.com

Ritu Santra, Student, Department of Electrical and Electronics Engineering, SRM Institute of Science and Technology, Chennai, Tamil Nadu, India. E-mail : ritusantra525@gmail.com

(C) The Authors. Published by Blue Eyes Intelligence Engineering and Sciences Publication (BEIESP). This is an open access article under the CC BY-NC-ND license (http://creativecommons.org/licenses/by-nc-nd/4.0/) country and it can fulfill the overwhelming demand of people by providing the continuous supply of electricity during the failure of main power grid. [3] According to World Health Organization report, Gurugram is the most polluted city in the world in terms of Air Pollution so over there is huge requirement of Energy which is produced by Renewable Resources.[2] According to Power Grid corporation of India , Smart grid can be solution for reducing pollution like Global warming by introducing the renewable resources.[1] According to Power Grid Corporation of India, Central and State government need to encourage consumers by providing regulatory framework for net metering tariff policy. Internet of Things [IOT] will be a great remedy for the very long distance communication as the data from the sensors can be stored in the microcontroller and can be easily accessible by User.

\section{LITERATURE SURVEY}

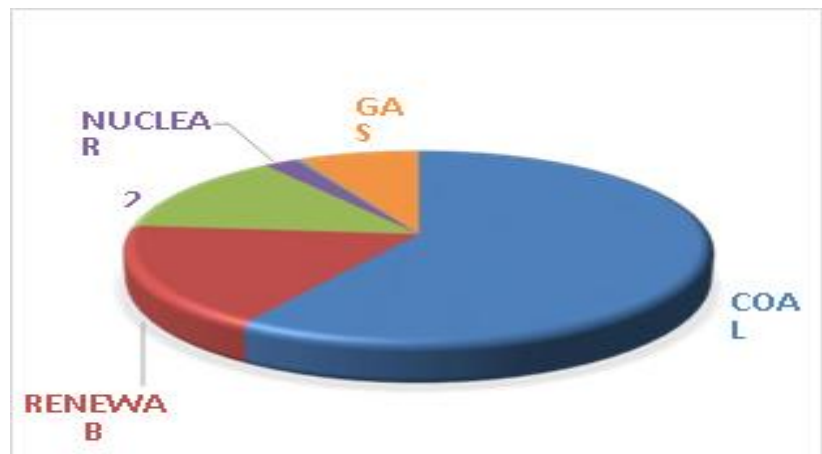

Fig.1. Installed capacity of energy in percentage

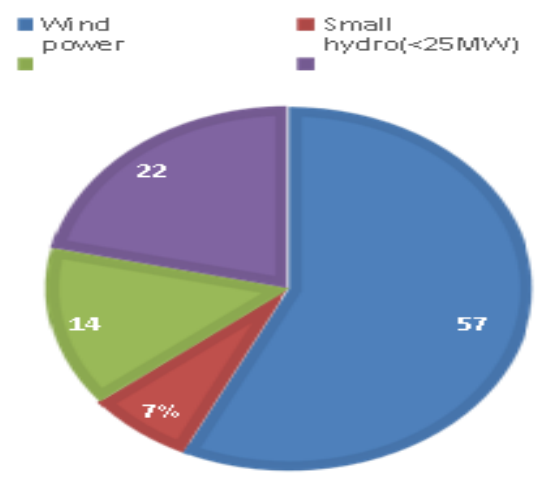

Fig.2. Installed Capacity of Renewable Energy

India is looking forward to "Transform the Indian power sector into a secure, adaptive, sustainable and digitally enabled ecosystem that provides reliable and quality energy for all with active participation of stakeholders".

Blue Eyes Intelligence Engineering 
A Micro-grid is an integrated system containing loads and energy resources which can either operate in off-grid mode or parallelly with the micro-grid. Micro turbines, wind, solar, fuel cells or other energy sources. Ability of the micro-grid to isolate from a larger network provides highly reliable electric power to its consumers.

\section{METHODOLOGY MICROGRID}

Microgrid is a group of interconnected electrical sources which either connect to or disconnect from the main power grid to able to operate in both grid-connected mode and islanded mode. The power in a microgrid can be obtained both from renewable and non-renewable resources. The renewable resources like solar and wind are widely used to obtain electricity. The system also comes with energy storage systems, like battery backup. These backup resources can be used in off-grid mode and also parallelly with the microgrid together. It's ability to isolate itself and work in a off-grid (standalone) mode makes it a high reliable system for electricity production.[4]

\section{INTERNET OF THINGS}

'Internet of Things' (IoT) refers to a technology in which the 'things' or any device with unique identities can sense, actuate, collect data and communicate with other 'things' via internet. The 'things' in this technology collect the data and send it to the cloud for storage and data analysis. The transfer and storage of data in cloud uses various communication protocols like Wi-Fi, Ethernet, Bluetooth, Zigbee etc. depending the range across which the data will be transferred. Hence, the devices can be controlled and monitored remotely. With the increasing developments in this century, IoT is playing a major role in connecting the world.[5]

\section{IMPLEMENTATION NET METERING CONCEPT}

Net metering is a concept in which, the owner of the microgrid can sell the excess energy produced to the power grid company and in return the owner will earn credits/incentives. The energy produced from solar or wind based microgrid system will be used in the house of the owner during the peak demand time duration. And the excess of the energy produced will be directly fed into the power grid, so that it can be used by other consumers. When the energy production is low or during the night time, the owner will draw energy from the power grid. A meter is to be installed in the premises of the owner, which will keep a track of the net exchange of energy to and from the power grid. And according to that meter, the owner will earn credits and need to pay for the energy he had drawn from the power grid.

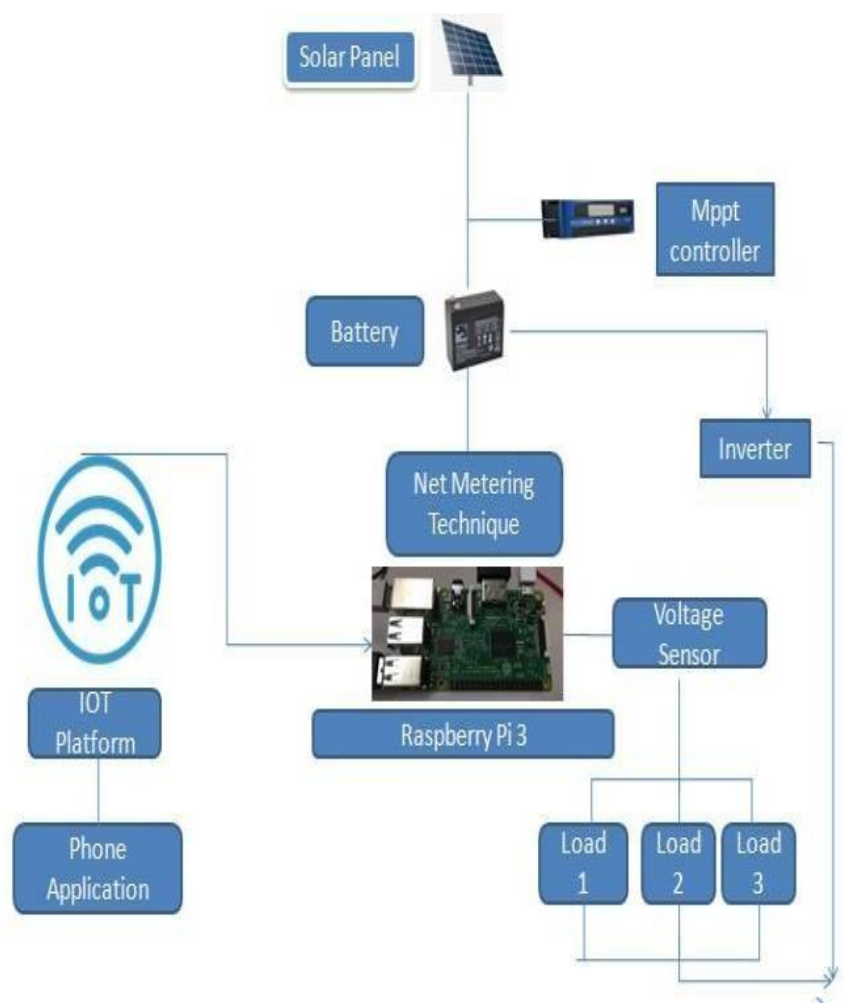

Fig.3.Smart Microgrid enabled Net Metering Technique

\section{SMART MANAGEMENT OF LOAD}

In this system, the load is connected to raspberry pi 3 which consists of sensors which provides the feedback to the raspberry pi 3 .The raspberry pi 3 controllers of 3 appliances or loads communicate to each other by a common controller through Machine to Machine communication. This communication is take place during the time peak load, so that one appliance can enter into the power saving mode, so that power will be saved.

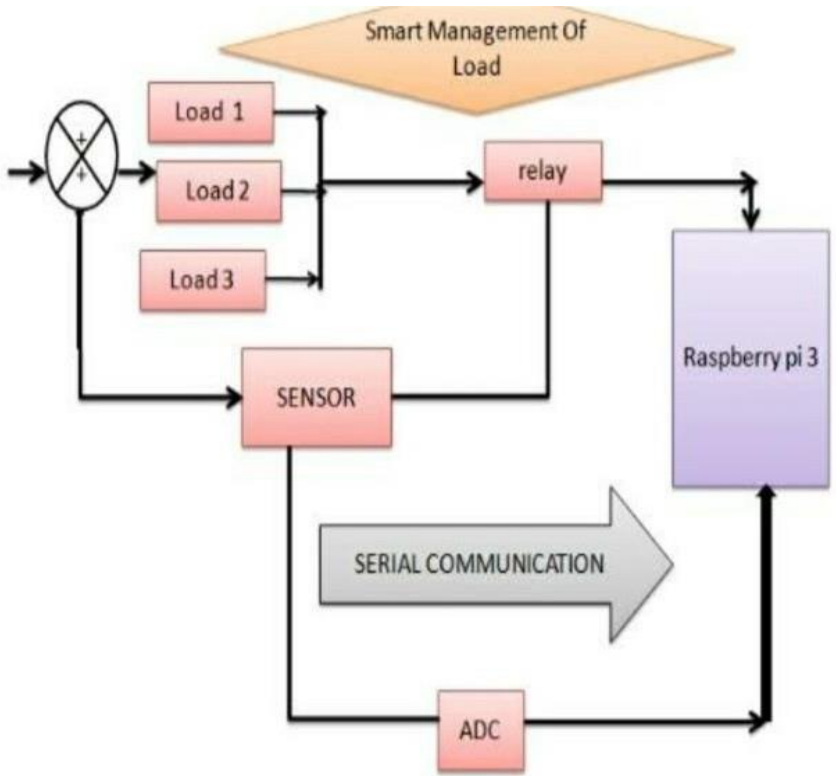

Fig.4. Smart Management of Load 


\section{FAULT DETECTION IN TRANSMISSION LINES}

This system consists of detecting and analyzing of faults in the Transmission Lines based on Internet Of Things. This design work on the basis of change in voltage values or change in current. This design is basically useful for Short-circuit fault, Line-line fault and Line to Ground Fault. This design also able to detect lightning stroke. After detection of fault that data will store in SD card inside the microcontroller \& then it can be transmitted tolocal Substation through Wi-Fi module. Unique IP address will be assigned to each microcontroller by which it will be identified. To make the system more reliable data analytics is required so compare the data with previous data \& then detect the causes of faults. The microcontroller (Raspberry pi 3) will be pre- programmed by Python since it will help establishing M2M communication. Finally, fault can be monitored on Cayenne's IOT platform. The Fault will cause loads to turn off. Similarly, when the fault will get cleared, the load will automatically get turn on. Sensors are installed in the transmission lines to monitor the state of current \& voltage.

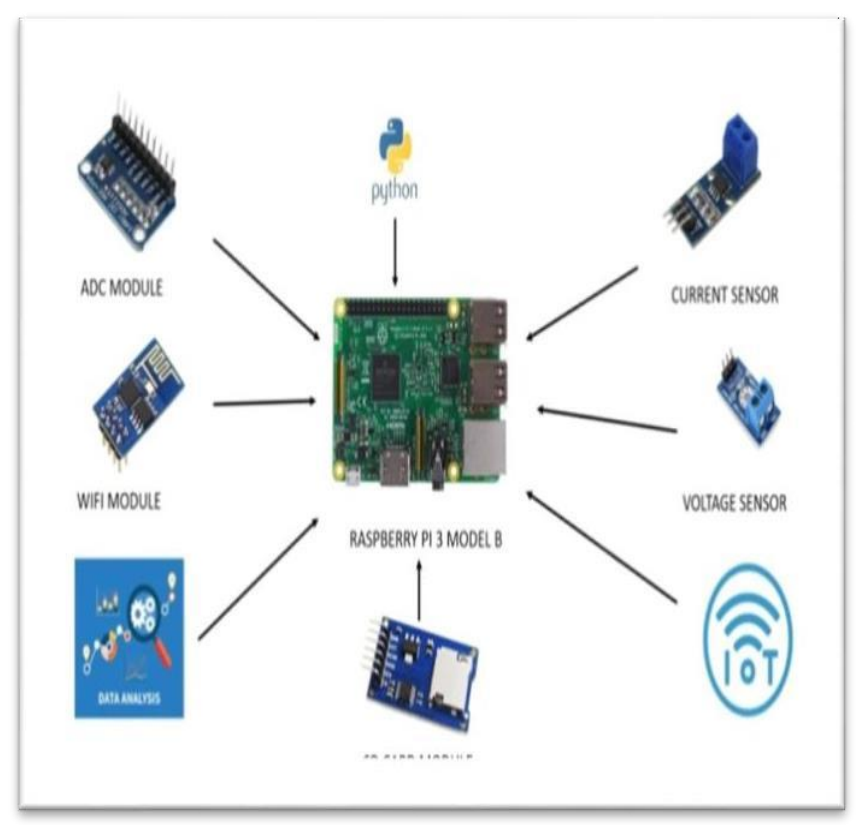

Fig. 5. Fault Detection in transmission lines

\section{RESULT}

The results from the sensor such as current sensor and voltage sensors are obtained on platforms like Cayenne and Thingspeak. The loads can be triggered online through Cayenne platform. The platform also gives the indication of the fault present in the particular system. Loads are being monitored on Cayenne's IOT platform. The data such as storage, current value, voltage value, switching on/off of loads can be done through using Cayenne's IOT platform. The IOT platform result shown in fig.6.

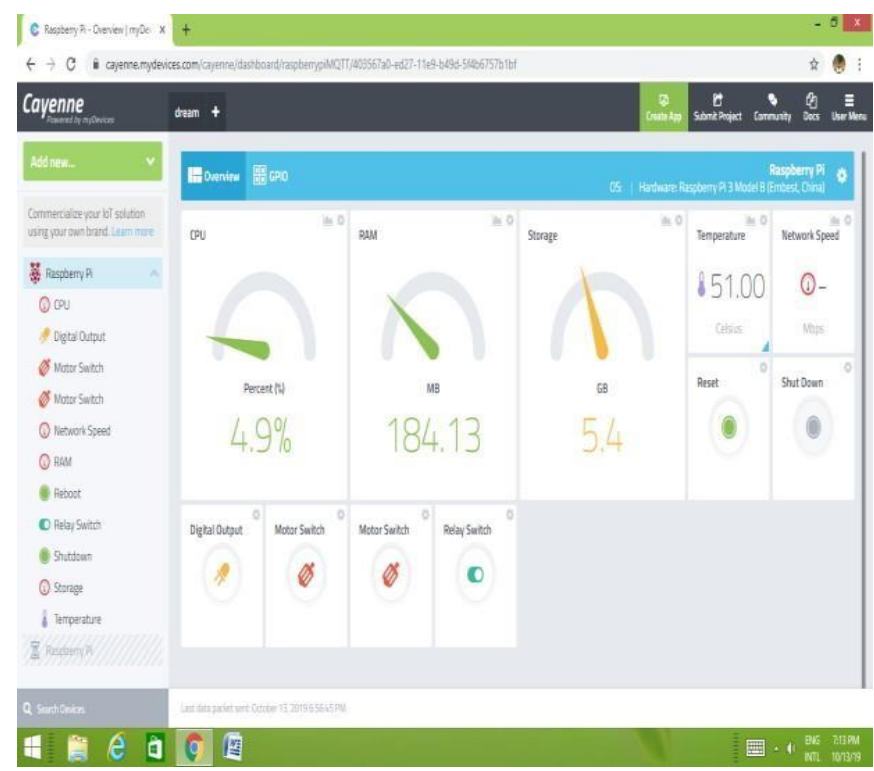

Fig. 6. Voltage Vs Time of a current Sensor through IOT

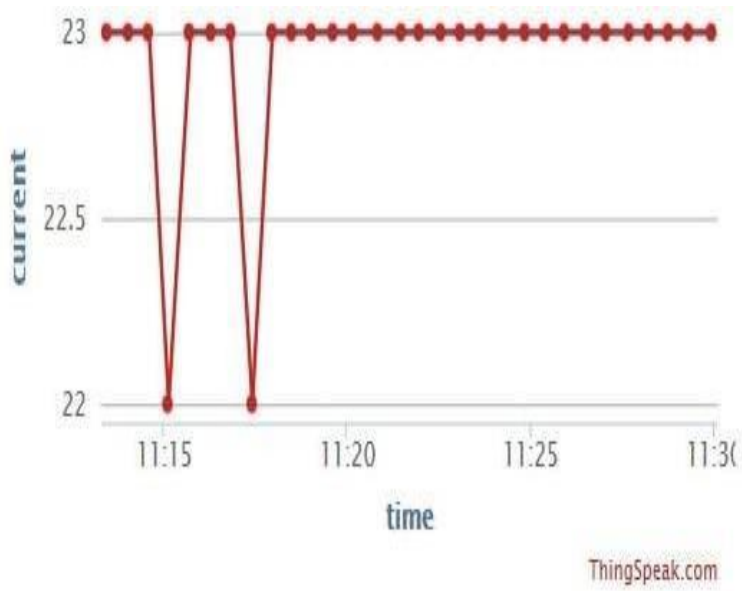

Fig 7. Current Vs Time of a current Sensor through IOT

The graph shown in the fig.7 depicts the values of current with respect to time. It shows that at 11:15am the current value is 22 $\mathrm{mA}$. As the time increases, around 11:17am it increases to $23 \mathrm{~mA}$. After decreasing at 11:18am gain, it rises up to $23 \mathrm{~mA}$ again and remains constant with time. Although there are certain fluctuations in the current, the current value remains constant after 11:18am shown in table 1 .

Table 1: Current Vs Time

\begin{tabular}{|l|l|l|}
\hline No of Trials & Current Value & Time \\
\hline 1. & $22 \mathrm{~mA}$ & $11: 15 \mathrm{am}$ \\
\hline 2. & $23 \mathrm{~mA}$ & $11: 17 \mathrm{am}$ \\
\hline 3. & $22 \mathrm{~mA}$ & $11: 18 \mathrm{am}$ \\
\hline 4. & $23 \mathrm{~mA}$ & $11: 20 \mathrm{am}$ \\
\hline 5. & $23 \mathrm{~mA}$ & $11: 25 \mathrm{am}$ \\
\hline
\end{tabular}

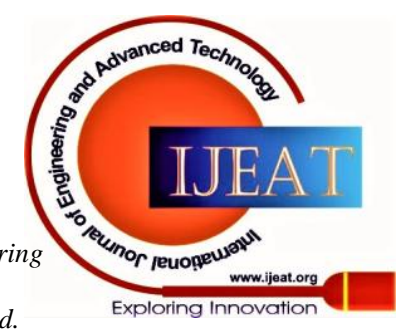




\section{Internet of Things Enabled Smart Microgrid}

The graph shown in figure .8. Depicts the variation of voltage with time. The average voltage obtained is $19.5 \mathrm{mV}$. The voltage remains zero but it rises to maximum $19.5 \mathrm{mV}$ and drops at $5 \mathrm{mV}$. The change in Voltage and current with respect to time can be monitored on IOT platform. For e.g. during the time of high load the fluctuation of load can be monitored using Cayenne's IOT platform shown values in table 2.

\section{Voltage}

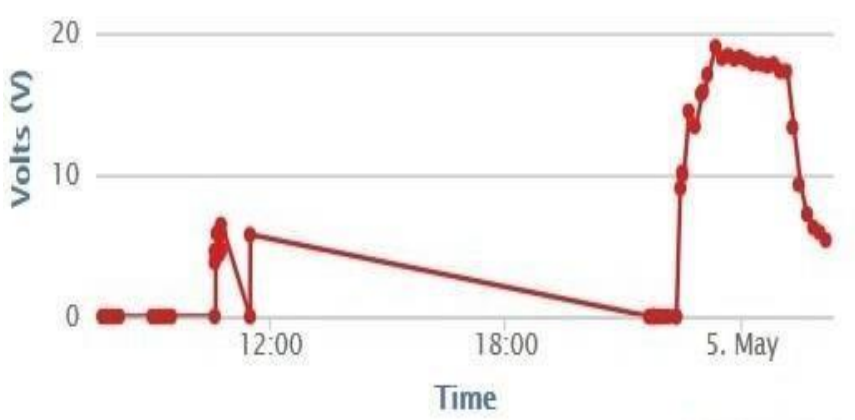

ThingSpeak.com

Fig .8. Current Vs Time of a current Sensor through IOT

Table 2: Voltage Vs Time

\begin{tabular}{|l|l|l|}
\hline No of Trials & $\begin{array}{l}\text { Average Voltage } \\
\text { Value }\end{array}$ & Time \\
\hline 1. & $10 \mathrm{mV}-18 \mathrm{mV}$ & $12 \mathrm{pm}-6 \mathrm{pm}$ \\
\hline 2. & $19: 5 \mathrm{mV}$ & After $6 \mathrm{pm}$ \\
\hline
\end{tabular}

\section{FUTURE SCOPE}

Microgrid is an excellent solution for providing continuous supply of power during the failure of main grid (Blackouts issues), it can also use in industries for providing addition power, and most importantly it can implemented in areas like island or undeveloped rural areas while the IOT can be a solution that offers the solution for detecting the fault and a convenience real-time technique to control and monitor the consumption of energy.

\section{CONCLUSION}

The focus of the microgrid is to provide power to every place where there's a deficiency of main power supply. By introducing this system, power will be supplied to like villages and many remotes areas. This smart microgrid system implemented with IOT technology will make it automated. One of the advantages of this system is its power supply can be monitored and controlled from any place and the microgrid can be very useful in the blackout conditions as it will be providing the supply from the battery back-up. The microgrid is incorporated with net metering concept smart energy distribution of power to the load by turning the appliances in power saving mode by the help of IoT platform in order to make power system reliable. This smart microgrid can be installed in every house of the country for promoting smart energy distribution, a smart way of energy saving, and ecofriendly technique, this can connect parallel to the main grid supply. Thus, by the implementation of this entire system power supplying, load management and fault detection process will accurate, fast, reliable and more effective. Hence this approach will promote the smart development.

\section{REFERENCES}

1. Power Grid corporation of India "Smart Grid Green Energy Corridor report".

2. World Health Organization Report of Air Pollution released in Geneva.

3. Government of India, Ministry of Science and Technology and Department of Science and Technology, New Delhi (2017) 'India Country Report on Research, Development and Deployment of Smart Grids in India.'

4. S. Sujeeth and Dr. O. V. Gnana Swathika (2018) 'IoT based automated protection and control of DC Microgrids', Proceedings of the Second International Conference on Inventive Systems and Control (ICISC 2018) - IEEE Xplore Compliant, pp.1422-1426

5. M.H.F Ahamed, U.D.S.D Dissanayake, H.M.P De Silva,

6. H.R.C.G.P Pradeep, N.W.A. Lidula (2016) 'Modelling and Simulation of a Solar PV and Battery Based DC Microgrid System', International Conference on Electrical, Electronics, and Optimization Techniques (ICEEOT) - 2016, pp.1706-1711.

7. Mohamad-Amin Nasr and Ehsan Nasr-Azadani (2017) 'System Performance in Microgrids based Hybrid PV Systems', IEEE 2017, pp.1-5.

8. Tai-Yeon Ku, Wan-Ki Park, Hoon Choi (2017) 'IoT Energy Management Platform for MicroGrid', 2017 IEEE $7^{\text {th }}$ International Conference on Power and Energy Systems, pp.106-110.

9. Andrea Zanella, Nicola Bui, Angelo Castellani, Lorenzo Vangelista and Michele Zorzi (2014) 'Internet of Things for Smart Cities', IEEE Internet of Things Journal, Vol.1, No.1, February 2014, pp.22-32

10. R.Zamora and A.Srivastava"Energy Management and contrpl algorithm for Integration of Energy storage within Microgrid". IEEE. $23^{\text {rd }}$ International Symposium on Industrial Electronics (ISIE..) 2014. pp.1805-1810.

11. V.S.K. Murthy Balijepalli.S.A. Khaparde and C.V.Dobariya(2010)'Deployment of MicroGrids in India',2010,pp.1-7

\section{AUTHORS PROFILE}

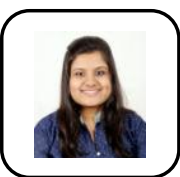

Sonali Dash, Student, Bachelor of Technology in Electrical and Electronics Engineering at SRM Institute of Science and Technology, Ramapuram. She is passionate and has a keen interest in the field of microgrid and electric vehicle (EV).Also have done projects in these fields and would like to have a career in them. She can be reached at email: sonalidash1316@gmail.com.

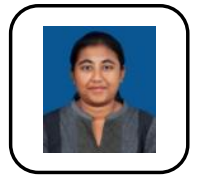

Ritu Santra, Student, Bachelor of Technology in Electrical and Electronics Engineering at SRM Institute of Science and Technology, Ramapuram. She is passionate and has a keen interest in the field of microgrid and electric vehicle (EV).Also have done projects in these fields and would like to have a career in them. She can be reached at email: ritusantra525@gmail.com. 